\title{
Diagnosis of Larval Stage (Metacercaria) of Two Eye Trematodes from Some Local Fishes by using Polymorphic Random Amplified DNA (PCR-RAPD)
}

\author{
Abdul Hussein H. Awad* and Hajer R. Manhel \\ Biology Department College of Education for Pure Science Basrah University Basrah, Iraq \\ *Corresponding author
}

\section{A B S T R A C T}

Keywords

Diplostomum spathaceum, PCR-RAPD.

Article Info

Accepted:

13 August 2016

Available Online:

10 September 2016
Genetic variations were found between the larval stage of Diplostomum spathaceum and Diplostomum spp. using Random Amplified Polymorphic DNA (PCR-RAPD). Nine primers each of which is composed of ten base oligonucleotid were selected. The number of bands were different, It ranged from 2-9. Both types of trematodes were distinguished by using this technique.

\section{Introduction}

The larval stage (metacercaria) for Diplostomum spathaceum and Diplostomum spp. affect the Lens and the aqueaos humer of the eyes of some local fish in the province of Basrah causing serious diseases. Random Amplified polymorphic DNA (RAPD) technique was used in the study. Nine random primers was selected to see genetic varations between the larval stage of both species. This technique has proven its efficiency in the broad areas of medicine and microbiology (Williams et al., 1990).

The larval stage metacercaria for Diplostomum spathaceum and Diplostomum spp. live in the eye of freshwater fishs and due to the great morphological similarity shown by this stage in the different species of eye trematode there is some difficulty in diagnosis. The identification of the larval stage is very important to know the life cycle of the parasite and distinguish it from other species that infect the eyes of fish (Mckeown and Irwin, 1995).

The present study aim to use RAPD technique to characterize the larval stage for both species due to the difficulty in diagnosis based on the phenotypic description.

\section{Materials and Methods}

The larval stage of Diplostomum spathaceum and Diplostomum spp. isolated from lenses of fish eyes (Cyprinus carpio, Tilapia zilli and Barbus luteus) and aqueous humer of Barbus luteus which have brought 
from Garmat Ali river was frozen immediately to $20^{\circ} \mathrm{c}$.

\section{DNA Extraction}

DNA for larval stage of both species was extracted according to Benito et al.(1993) with some modification.

\section{Detection of DNA}

\section{Agarose gel preparation}

The samples was left on the agarose gel concentration $1 \%(0.25 \mathrm{mg}$ agarose type Scharlab SL) Spanish origin . $0.1 \mu \mathrm{L}$ Ethidium Bromid stain was added. The gel poured into the mold and left 10-15 minute for the purpose of cohesion.

\section{Agarose Gel Electrophoresis (AGE)}

The template was immersed in the main basin content solution (10X TBE) .9 ul of DNA output mixed with 3 um Bromophenol Blue stain and the mixture is injected into the pits equipped with the power supply 80 Volt and 120 Mali ambir for half an hour The gel is examined in UV light.

\section{The assess of the DNA}

The presence of the DNA was detected using UV light type of Cleaver Scientific Itd (CS). The thickness of the bands of the DNA as well as presence or absences of a smear that indicate the presence of impurities which reflects the efficiency and purity of DNA extraction.

\section{Amplified of the DNA}

The DNA was amplified using Williams $e t$ al. (1990) method.

$20 \mu \mathrm{L}$ from Master Mix equipped by Bioneer company was used. The PCR Buffer 10X consists of $10 \mathrm{mM}$ Tris-HCL
(pH 9.0) , $30 \mathrm{mM} \mathrm{KCL}, 1.5 \mathrm{mM} \mathrm{MgCl}_{2}, 1 \%$ gelatin and dNTPs ( dATP, dTTP ,dCTP ,dGTP ) at concentration $250 \mathrm{ul}, 1 \mu \mathrm{L} \mathrm{Taq}$ DNA polymerase. Nine random primers equipped by Bioneer company (Table 1).Tubes was numbered with sample number that was added to the tube and by the initiator added to the tube as follows:

\begin{tabular}{|l|l|l|}
\hline gradation & component & size \\
\hline 1 & DNA & $5 \mu \mathrm{L}$ \\
\hline 2 & Distilled water & $7.5 \mu \mathrm{L}$ \\
\hline 3 & Primer & $1 \mu \mathrm{L}$ \\
\hline Total & & $13.5 \mu \mathrm{L}$ \\
\hline
\end{tabular}

The component mixed well by Vortex for 30 second. The samples are numbers 1-9 and arranged on the $\mathrm{X}$-axis, while primers arranged on the $\mathrm{Y}$-axis in order to facilitate the handling of the specimens.

The tubes transferred to Thermocycler Cleaver Scientific (CS) to start amplified interaction. The following interaction program was chosen:

\begin{tabular}{|l|l|l|l|}
\hline Steps & temperature & Time & Cycles \\
\hline Denaturation 1 & $95^{\circ} \mathrm{c}$ & $5 \mathrm{~min}$ & 1 cycle \\
\cline { 1 - 3 } Denaturation 2 & $94{ }^{\circ} \mathrm{c}$ & $1 \mathrm{~min}$ & \multirow{2}{*}{} \\
\cline { 1 - 3 } Annealing & $36^{\circ} \mathrm{c}$ & $1 \mathrm{~min}$ & \multirow{2}{*}{40 cycle } \\
\cline { 1 - 3 } Extension 1 & $72{ }^{\circ} \mathrm{c}$ & $2 \mathrm{~min}$ & \\
\cline { 1 - 3 } Extension 2 & $72{ }^{\circ} \mathrm{c}$ & $8 \mathrm{~min}$ & 1 cycle \\
\hline
\end{tabular}

Agarose gel at concentration $2 \%$ was prepared with same way that mentioned earlier. The Samples and and the Ladder was carried in the pits and immersed in a solution of the gel slab (TPE, $\mathrm{PH}=8$ ) the polar linked to power supply 70 Volt, 120 Ampere for 3 hours. The gel left was examined under UV light and photographed using the imaging device of the type Cleaver Scientific (CS). Molecular weights of multiplying segments were estimated according as to know molecular sizes standard. 


\section{Results and Discussion}

The number of multiplying bands for both species (Photo 1, Table 2) of trematodes was counted according to the program of photo capt M W (2000) by entering all the data into the computer.

The data were analyzed to estimate molecular weights (Photo 2) and to identify the resulting bands during the replication process (Nei and Li, 1979). The multiplication results of the two species were anlyzed to find Genetic Similarity (Taple 3) using the following equation:

$\mathrm{SDd}=2 \mathrm{NDd} / \mathrm{ND}+\mathrm{Nd}$

SDd: represent Genetic Distance where D, d it represents the two species of trematodes with genotype required to find similarities between them.

D: metacercaria (Diplostomum spathaceum).

d: metacercaria (Diplostomum spp.).

NDd: represent the number of share bands for two species.

ND: total bands of the first species.

$\mathrm{Nd}$ : total bands of the second species.

The values of Genetic Similarities were calculated of the two species according to the following equation:

$\mathrm{SDd}=2(6) / 46+49$

$$
=0.125
$$

To find Genetic Distance between the two species the following equation was applied:

GDDd= 1- GSDd

GDDd: represent Genetic Distance for D,d of both species.

GSDd: represent Genetic Similarities for both species, The Genetic Similarities of both species was:

$$
\begin{aligned}
& \text { GDDd }=1-0.125 \\
& =0.875
\end{aligned}
$$

In Iraq, no study concerning the use of RAPD technique with Diplostomum. The previous studies were based on phenotypic and morphological description of this parasite which is feasible at the present time due to the tremendous progress made in the use of PCR technique.

The RAPD technique characterized by speeds and shorten the steps, small amount of DNA needed (Williams et al.,1990).

This technique is used to characterize some of the similar species which are difficult to distinguish on the basis of shape and phenotypic description.

It helps a lot to differentiate between species and strain of bacteria, fungi, plants and som trematodes (Wlesh and Mc Clelland, 1990; Tigh et al., 1994) 
Table.1 The names and the sequences of nine random primers used in the study

\begin{tabular}{|l|l||r|}
\hline Primer & Primers Sequence & GC\% \\
\hline \hline OPA .01 & 5 CAGGCCCTTC 3 & $\mathbf{7 0 \%}$ \\
OPA .02 & 5 TGCCGAGCTG 3 & $\mathbf{7 0 \%}$ \\
\hline OPA .03 & 5 AGTCAGCCAC 3 & $\mathbf{7 0 \%}$ \\
OPA .04 & 5 AATCGGGCTG 3 & $\mathbf{7 0 \%}$ \\
OPA .05 & 5 AGGGGTCTTG 3 & $\mathbf{6 0 \%}$ \\
OPA .06 & 5 GGTCCCTGAC 3 & $\mathbf{7 0 \%}$ \\
OPA .07 & 5 GAAACGGGTG 3 & $\mathbf{6 0 \%}$ \\
OPA .08 & 5 GTGACGTAGG 3 & $\mathbf{6 0 \%}$ \\
OPA .09 & 5 GGGTAACGCC 3 & $\mathbf{7 0} \%$ \\
\hline
\end{tabular}

Table.2 Band numbers showed by the nine primers of the two trematodes

\begin{tabular}{|c|c|c|c|c|c|c|c|c|c|}
\hline \multirow{2}{*}{ species } & \multicolumn{10}{|c|}{ Primers } \\
\cline { 2 - 11 } & OPA1 & OPA2 & OPA3 & OPA4 & OPA5 & OPA6 & OPA7 & OPA8 & OPA9 \\
\hline 1 & 9 & 6 & 5 & 5 & 7 & 0 & 5 & 4 & 5 \\
\hline 2 & 4 & 4 & 2 & 7 & 5 & 8 & 4 & 8 & 7 \\
\hline $\begin{array}{c}\text { Joint } \\
\text { bands }\end{array}$ & 0 & 0 & 2 & 0 & 2 & 0 & 1 & 1 & 0 \\
\hline \hline
\end{tabular}

Table.3 Genetic Similarity and Genetic Distance of the two trematodes by using the nine primers

\begin{tabular}{||c|c|c|c|c|c|c|c|c|c||}
\hline Primers & OPA1 & OPA2 & OPA3 & OPA4 & OPA5 & OPA6 & OPA7 & OPA8 & OPA9 \\
\hline \hline $\begin{array}{c}\text { Genetic } \\
\text { Similarity }\end{array}$ & 0 & 0 & 1.75 & 0 & 0.33 & 0 & 0.22 & 0.16 & 0 \\
\hline $\begin{array}{c}\text { Genetic } \\
\text { Distance }\end{array}$ & 1 & 1 & 0.75 & 1 & 0.66 & 1 & 0.78 & 0.84 & 1 \\
\hline
\end{tabular}


Table.4 Molecular weight of the bands by using the nine primers

\begin{tabular}{|c|c|c|c|c|c|c|c|c|c|c|c|c|c|c|c|c|c|c|}
\hline \multicolumn{19}{|c|}{ M.W. } \\
\hline \multirow[t]{2}{*}{$\bar{M}$} & \multicolumn{2}{|c|}{$\overline{\text { OPA1 }}$} & \multicolumn{2}{|c|}{$\overline{\mathrm{OPA} 2}$} & \multicolumn{2}{|c|}{ OPA3 } & \multicolumn{2}{|c|}{$\overline{\text { OPA4 }}$} & \multicolumn{2}{|c|}{ OPA5 } & \multicolumn{2}{|c|}{$\overline{\text { OPA6 }}$} & \multicolumn{2}{|c|}{$\overline{\text { OPA7 }}$} & \multicolumn{2}{|c|}{ OPA8 } & \multicolumn{2}{|c|}{ OPA9 } \\
\hline & D1 & d1 & D2 & d2 & D3 & d3 & D4 & d4 & D5 & d5 & D6 & d6 & D7 & d7 & D8 & d8 & D9 & d10 \\
\hline 2000 & 900 & 600 & 550 & 350 & 500 & 250 & 1600 & 700 & 1200 & 510 & & 700 & 730 & 420 & 690 & 810 & 600 & 590 \\
\hline 1600 & 800 & 520 & 500 & 300 & 410 & 210 & 600 & 600 & 800 & 480 & & 530 & 510 & 380 & 510 & 790 & 410 & 310 \\
\hline 1200 & 660 & 400 & 450 & 200 & 250 & & 410 & 500 & 710 & 380 & & 495 & 380 & 290 & 399 & 570 & 280 & 295 \\
\hline 1000 & 580 & 295 & 400 & 180 & 210 & & 220 & 410 & 690 & 250 & & 420 & 300 & 240 & 340 & 460 & 250 & 250 \\
\hline 900 & 500 & & 330 & & 190 & & 200 & 370 & 510 & 200 & & 370 & 240 & & & 400 & 100 & 200 \\
\hline 800 & 470 & & 280 & & & & & 320 & 380 & & & 310 & & & & 340 & & 180 \\
\hline 700 & 370 & & & & & & & 250 & 190 & & & 230 & & & & 290 & & 150 \\
\hline 600 & 340 & & & & & & & & & & & 195 & & & & 260 & & \\
\hline 500 & 250 & & & & & & & & & & & & & & & & & \\
\hline 400 & & & & & & & & & & & & & & & & & & \\
\hline 300 & & & & & & & & & & & & & & & & & & \\
\hline 200 & & & & & & & & & & & & & & & & & & \\
\hline 100 & & & & & & & & & & & & & & & & & & \\
\hline
\end{tabular}


Photo.1 RAPD profiles of the two larval stage of parasites with nine primers. M: Ladder, D1D9: multiplying bands of D. spathaceum. D1-d9: multiplying bands of Diplostomum spp.

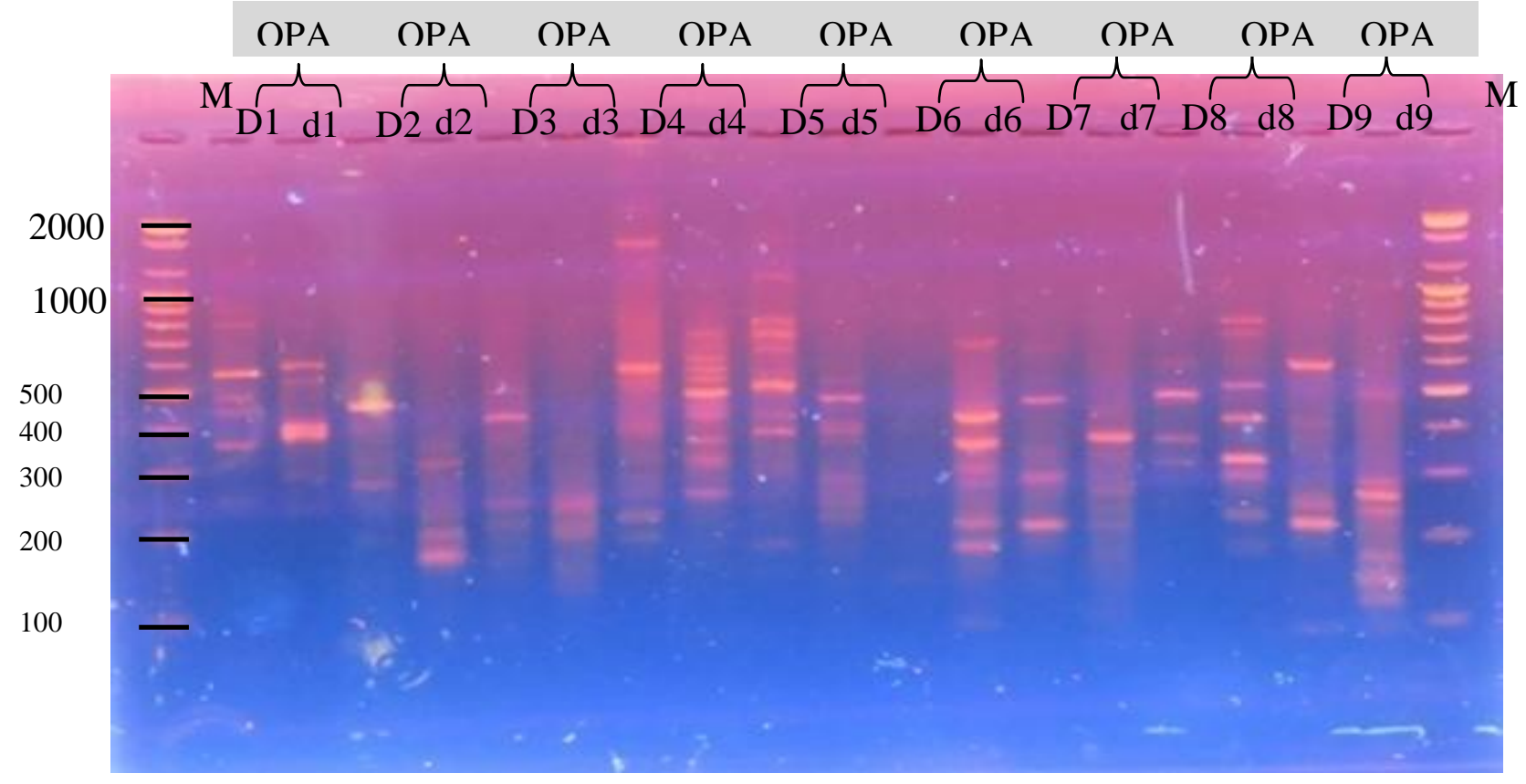

Photo.2 Molecular weight of the ladder

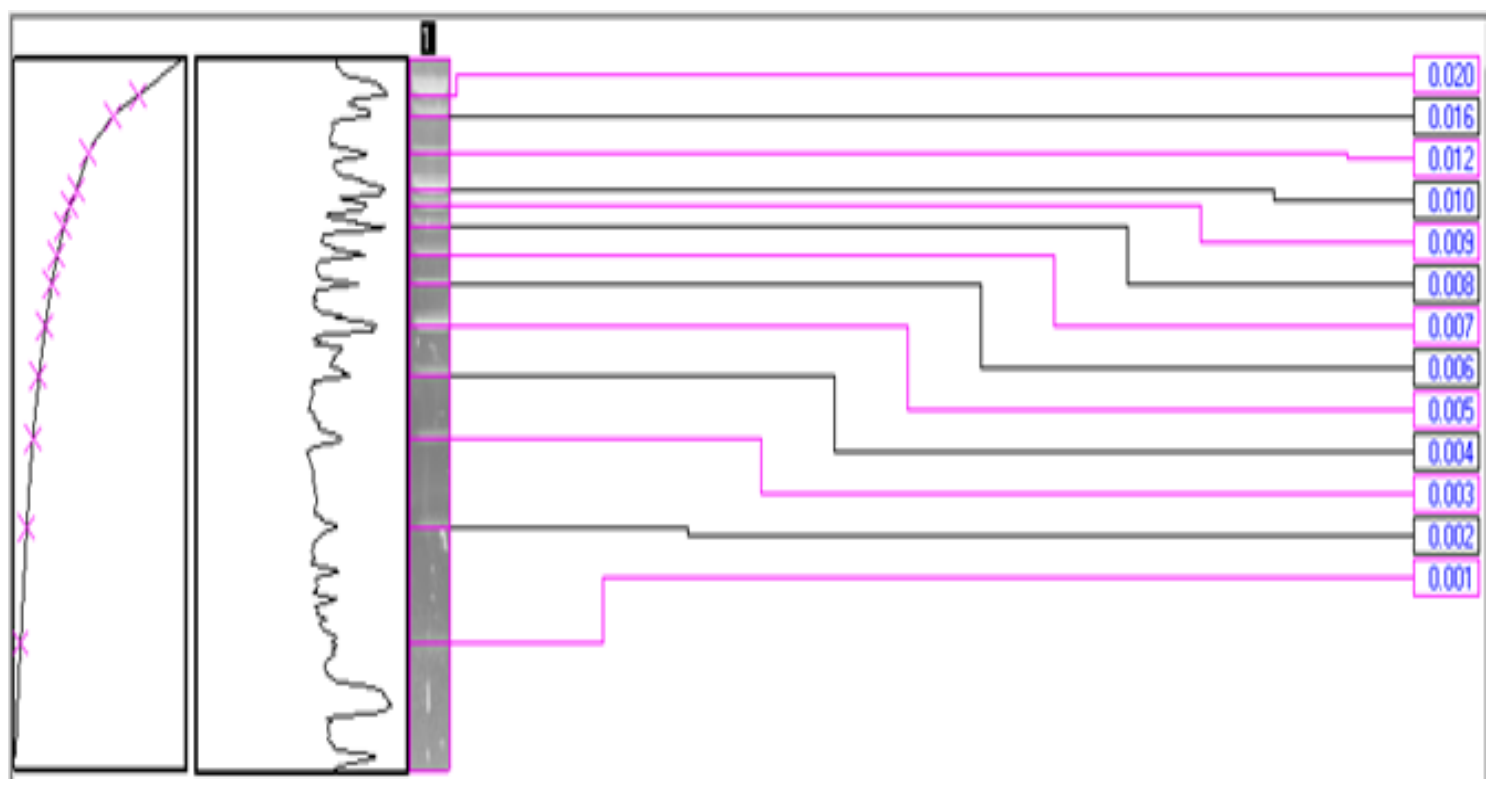


Photo.3 Agarose gel electrophoresis showing the RAPD profiles of the larval stage of the two parasites

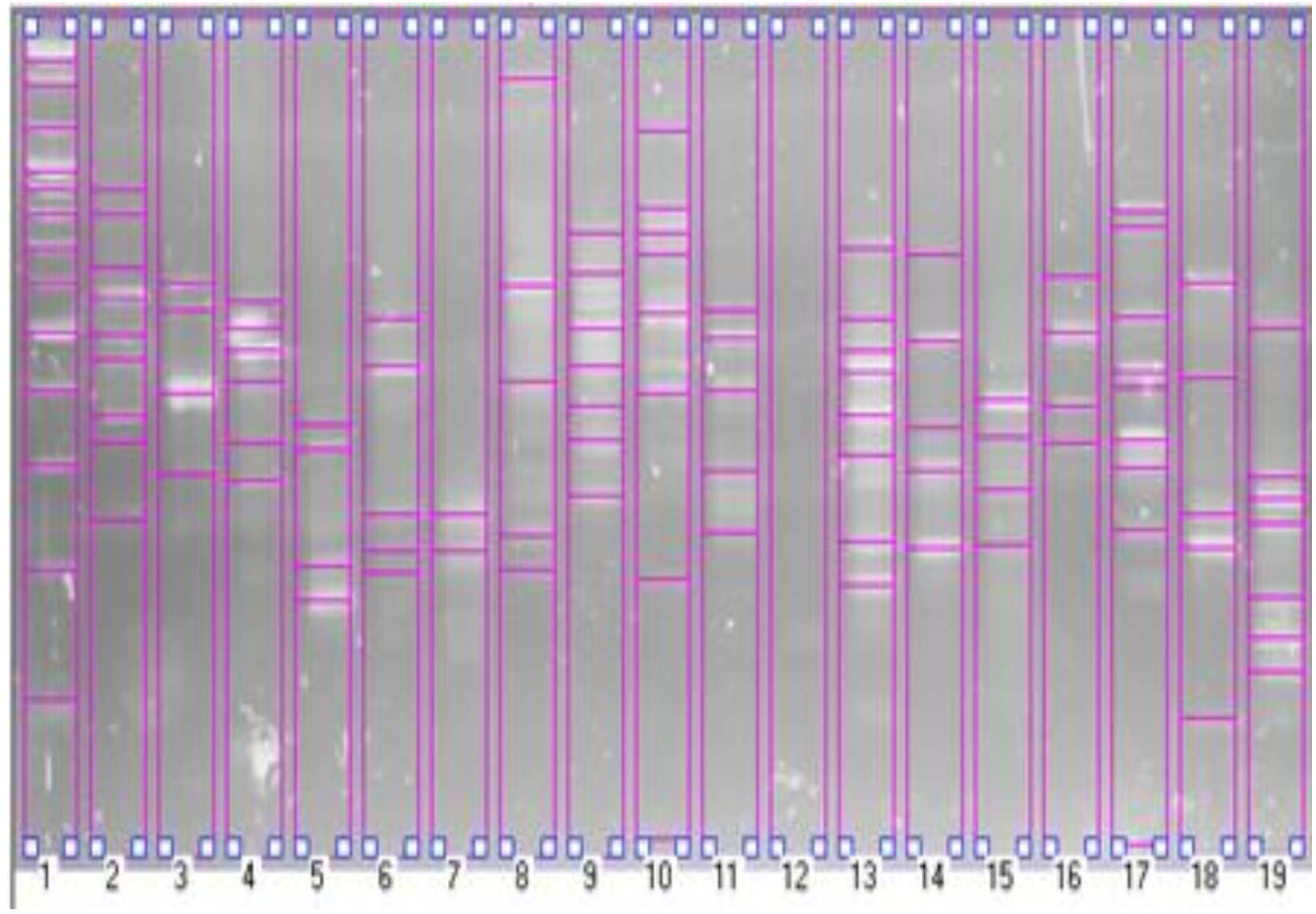

The Genetic Polymorphic was detected by comparing the multiplying forms of binds which rang from 2-9 and estimated the molecular weight between them The primers OPA1,OPA2,OPA4,OPA6 and OPA9 did not gave any share bands while the primers OPA3 and OPA5 gave two bands.The primers OPA7 and OPA8 gave one shared band only

There are many differences in the bands formed between the two species particularly the bands with M.W. between 200-1000 (Table 4.). The apperance of bands which different in number and location on the gel agarose show the difference in molecular weight of those bands which reflect genetic difference between the larval stage of both species. The genetic similarities value
(0.125) and genetic distance (0.875) showed the large genetic distance between both species. On the basis of this study there are two species of Diplostomum (Diplostomum spathaceum \& Diplostomum spp). infect the eyes of local fish in Basrah Province.

\section{References}

Benito, C., Figueiras, A.M., Zaragozal, C., Gallego, F.j., Dela Penal, A. 1993. Rapid identification of Trijticeae geno types from single seed using the polymerase chain reaction. J. Plant Mol. Biol., 21: 181-183.

Mckeown, C.A. \& Irwin, S.W.B. 1995. The life cycle stages of three Diplostomum species maintained in the laboratory. Int. J. Parasitol., 25: 897-906. 
Nei, M., Li, W.H. 1979. Mathematical model for studing genetic varation in terms of restriction endouncleases proceeding of the National Academy of science, USA. 74 (Cited by Hefity, R, J.1997).

Tigh, P.J., Goyal, P.K., Wilson, Z.A., Wakelin, D. \& Pritchard, D.I. 1994. Analysis of genetic variation in isolates of Trichinella using random ampliphied polymorphic DNA. Mol.
Biochem. Parasitol., 63: 175-178.

Williams, K.J., Kubelik, A., Livak, K., Rafalski, J. \& Tingey, S. 1990. DNA polymorphism amplified by arbitrary primers are useful as genetic markers. Nucleic acids Res., 18: 6531-6535.

Wlesh, J., Mc Clelland, M. 1990. Fingerprinting genomes using PCR with arbitrary primers. Nucleic Acids Res., 18: 7213-7218.

\section{How to cite this article:}

Abdul Hussein H. Awad and Hajer R. Manhel. 2016. Diagnosis of Larval Stage (Metacercaria) of Two Eye Trematodes from Some Local Fishes by using Polymorphic Random Amplified DNA (PCR-RAPD). Int.J.Curr.Microbiol.App.Sci. 5(9): 282-289.

doi: http://dx.doi.org/10.20546/ijcmas.2016.509.032 